\title{
Evolution of the diameters of the largest healthy and atretic follicles during the human menstrual cycle
}

\author{
A. Gougeon and Brigitte Lefèvre
}

\begin{abstract}
Physiologie et Psychologie de la Reproduction humaine, INSERM U-187, 32 rue des Carnets, 92140 Clamart, France
\end{abstract}

\begin{abstract}
Summary. Analysis of ovaries from 31 women with normal ovarian function permitted study of the diameter of the largest healthy and atretic follicles during the menstrual cycle. The follicle destined to ovulate is selected during the early follicular phase (Days 1-5). Throughout the cycle the diameter of the largest healthy follicles, with the exception of the dominant follicle, did not exceed, on average, $6 \mathrm{~mm}$ during the follicular phase and $4 \mathrm{~mm}$ during the luteal phase. Consequently, excluding the dominant follicle during the second half of the follicular phase, the largest follicles present in the human ovary are atretic.

From these data, it was concluded that a new ovulation could not occur very soon after a spontaneous or experimentally induced premature disappearance of the dominant follicle or the corpus luteum of the cycle.
\end{abstract}

\section{Introduction}

Recent experimental studies of folliculogenesis, primarily in monkeys, have enabled considerable progress to be made in our understanding of the intricate mechanisms governing this process in primates (for review see Hodgen, 1982). In the rhesus monkey (Goodman, Nixon, Johnson \& Hodgen, 1977) and in women (Nilsson, Wikland \& Hamberger, 1982), ablation of the follicle destined to ovulate or of the corpus luteum of the cycle at the start of the luteal phase is followed by a new ovulation about 2 weeks later. This interval, identical to the duration of the follicular phase, has been considered essential for the recruitment of a new dominant follicle and its growth to ovulatory size. However, the experimental observations require further investigation because there is no information on the size of those follicles from which the new dominant follicle is recruited.

In an attempt to solve this question, and determine at which moment in a normal cycle the dominant follicle may be identified, the evolution of the diameter of the largest healthy and atretic follicles during the human menstrual cycle has been analysed.

\section{Materials and Methods}

Sampling. Ovaries were obtained during gynaecological surgery (ovariectomy for carcinoma of the breasts or cervix, hysterectomy for fibroids). They were fixed in Bouin's fluid or a mixture of alcohol, formaldehyde and acetic acid, processed by routine histological methods and then serially sectioned at $10 \mu \mathrm{m}$.

Ovarian function was considered to be normal after verification of the following criteria: (i) absence of morphological pathology of the ovary, (ii) regular menstrual cycles $(28 \pm 3$ days) determined over the 3 previous cycles and (iii) occurrence of ovulation in each of the preceding 3 
cycles, confirmed by the presence of corpora lutea at various stages of degeneration. After verification of these criteria, 31 sets of samples were retained for study, coming from patients aged between 19 and 49 years (mean \pm s.d. $=38.9 \pm 7.5$ years).

Determination of the cycle day. The date of the previous menstrual period, ovarian histology (presence of a preovulatory follicle or a cyclic corpus luteum) and, in certain cases, endometrial histology (18 cases) and circulating gonadotrophin and steroid levels (12 cases) were used to determine the stage of the cycle at which the samples were taken. The theoretical 28-day menstrual cycle was subdivided into 6 stages: early (Days 1-5), middle (Days 6-10) and late (Days 11-14) follicular phase, and early (Days 15-19), middle (Days 20-24) and late (Days 25-28) luteal phase.

Calculations. Follicular dimensions were measured with an ocular micrometer. The basement membrane of the follicle was taken as the outer limit of the follicle. Follicular diameter was taken as the mean of 3 measurements: the first two were measurements taken at right angles on the section in which the follicle area was maximal, and the third was the number of sections in which the follicle was visible multiplied by $10 \mu \mathrm{m}$ (the thickness of one section).

Mitotic and pycnotic indices were calculated for each follicle. Calculations were performed on 4-6 sections from different places located equidistant from one another. For each section, the number of granulosa cells was the product of the volume occupied by the granulosa cells and their cellular density. Cellular density was measured with a squared reticle in 5 different areas of the follicle. All the cells undergoing mitosis or pycnosis in the same section were then counted. From these data, the proportion of cells in mitosis (mitotic index) or in pycnosis (pycnotic index) was calculated for 1000 granulosa cells in each section.

Healthy follicles were distinguished from atretic follicles on the basis of 3 previously described criteria (Gougeon, 1979): mitotic and pycnotic indices of the granulosa cells, morphological aspect of the oocyte and shape of the follicle.

The statistical significance of the observed differences was determined by paired $t$ tests and Student's $t$ tests as appropriate.

\section{Results}

Evolution of the diameter of the largest healthy and atretic follicles during the cycle

During the first half of the cycle, the largest healthy follicle developed in a continuous manner (Table 1) and the diameter of this follicle was significantly greater than that of other large healthy follicles in the ipsilateral or contralateral ovaries $(P<0.01)$.

The diameter of the largest healthy-non-dominant follicle (Table 1) in the ipsilateral or contralateral ovaries varied little with the stage of the cycle, usually being between 3 and $5 \mathrm{~mm}$ except in the late follicular phase when it fell from $4.20 \pm 0.50$ (Days 6-10) to $1.90 \pm 0.45 \mathrm{~mm}$ (Days 11-14) $(P<0.01)$.

During the follicular phase and early luteal phase, atretic follicles with a diameter greater than $9 \mathrm{~mm}$ were often seen (Table 1), usually in the contralateral ovaries. In the mid- and late-luteal phases the diameter of the largest atretic follicles did not exceed $6 \mathrm{~mm}$. Therefore, excluding the follicle destined to ovulate during the second half of the follicular phase, the largest follicles present in the human ovary during the cycle were atretic.

\section{Early identification of the dominant follicle}

During the early follicular phase the mean size of the largest healthy follicle was significantly greater than the second largest healthy follicle in the same ovary, and also greater than the largest healthy follicle in the contralateral ovary $(P<0.01)$. However, except for its size, the largest healthy follicle was not morphologically different with respect to vascularization and theca interna or granulosa layers from other large healthy follicles. The first changes in the follicular histology 
Table 1. The mean diameter ( $\mathrm{mm}$ ) of (a) the largest healthy follicle, (b) the second largest healthy follicle and (c) the largest atretic follicle in the ovulatory or the contralateral ovary throughout the menstrual cycle of women

\begin{tabular}{|c|c|c|c|c|c|c|}
\hline \multirow[b]{2}{*}{ Ovary } & \multicolumn{6}{|c|}{ Day of cycle } \\
\hline & $(n \stackrel{2}{=} 5)$ & $\begin{array}{c}7 \\
(n=4)\end{array}$ & $\begin{array}{c}12 \\
(n=7)\end{array}$ & $\begin{array}{c}17 \\
(n=5)\end{array}$ & $(n=6)$ & $\begin{array}{c}26 \\
(n=4)\end{array}$ \\
\hline
\end{tabular}

(a) Largest healthy follicle Ovulatory Contralateral

$6.9 \pm 0.5 \quad 13.3 \pm 1 \cdot 2 \quad 18 \cdot 8 \pm 0.5$

$* 4 \cdot 2 \pm 0.4 \quad \dagger 3.9 \pm 0.6 \quad+1 \cdot 2 \pm 0.6$

$3 \cdot 4 \pm 1 \cdot 2$

$2 \cdot 6 \pm 1 \cdot 1$

$2 \cdot 8 \pm 0.8$

(b) Second largest healthy follicle

Ovulatory

Contralateral

$* 3 \cdot 5 \pm 1 \cdot 0$

$* 5 \cdot 8 \pm 1 \cdot 2$

$+2 \cdot 4 \pm 0 \cdot 7$

$2.8 \pm 0.9$

$2 \cdot 5 \pm 0.4$

$4 \cdot 1 \pm 0.8$

(c) Largest atretic follicle

Ovulatory

Contralateral

$2.8 \pm 0.7$

$3 \cdot 3 \pm 0 \cdot 7$

$1 \cdot 0 \pm 0 \cdot 7$

$2 \cdot 2 \pm 0.7$

$1 \cdot 2 \pm 0 \cdot 2$

$1 \cdot 2 \pm 0.5$

$0 \cdot 6 \pm 0 \cdot 1$

$1 \cdot 2 \pm 0.5$

$7 \cdot 0 \pm 1 \cdot 2$

$5 \cdot 0 \pm 1 \cdot 0$

$5 \cdot 2 \pm 0 \cdot 7$

$3.2 \pm 1 \cdot 1$

$5.0 \pm 0.7$

$2 \cdot 3 \pm 0.9$

$5.0 \pm 0.8$

$8.0 \pm 1.7$

$7 \cdot 4 \pm 4 \cdot 1$

$7 \cdot 4 \pm 0 \cdot 8$

$3 \cdot 1 \pm 1 \cdot 1$

$3.9 \pm 0.5$

$5 \cdot 6 \pm 0.3$

Values are mean \pm s.e.m. for the no. of samples in parentheses.

Values significantly different from the diameter of the largest healthy follicle in the ovulatory ovary; ${ }^{*} P<0.01$, $\dagger P<0.001$.

appeared in the mid-follicular phase for follicles with a diameter larger than $13 \mathrm{~mm}$, and such follicles showed increase of the thecal vascularization, hypertrophy of theca cells and thickening of the granulosa layer. These changes enabled easy identification of the dominant follicle from other large healthy follicles.

When the follicle was smaller than $13 \mathrm{~mm}$, the lack of morphological difference between the largest healthy follicle and other large healthy follicles made the criterion of size insufficient for use as a sole factor for identification of the dominant follicle. A follicle with a diameter smaller than that of the largest follicle could therefore, if it has a significantly higher mitotic activity than the latter, make up its growth delay within a few days. Consequently, among a population of large healthy follicles presenting the same histological characteristics, it is only possible to state that the dominant follicle has been chosen if at least two conditions are satisfied: (i) a healthy follicle with a diameter significantly greater than that of other healthy follicles must be present, and (ii) no follicle smaller than the largest healthy follicle should have a mitotic index significantly greater than that of the latter.

To determine the stage of the menstrual cycle when the selection of the follicle destined to ovulate is made, the mitotic index and diameter of the 3 largest healthy follicles present in the ovaries were examined in the late-luteal phase, and then in the early- and mid-follicular phases (Text-fig. 1). In the late-luteal phase there was a significant difference $(P<0 \cdot 01)$ in size between the two largest healthy follicles. Examination of the mitotic index, however, revealed that the largest follicle could not always be considered as the chosen follicle, because some smaller follicles had a significantly greater mitotic index $(P<0.05)$ (Text-fig. 1). However, during the early follicular phase there was a significant difference $(P<0.01)$ between the diameters of the two largest follicles, and the largest follicle could be considered as selected since no smaller follicle had a significantly greater mitotic index (Text-fig. 1). During the mid-follicular phase the difference in size between the two largest healthy follicles remained significant $(P<0.01$ and $P<0.001)$. In 3 women (Text-fig. 1) the third largest healthy follicle showed a mitotic index significantly greater than that of the 2 larger follicles $(P<0.01$ and $P<0.001)$. However, the size attained by the largest follicle, and the start of the morphological changes affecting its thecal vascularization and the theca interna and granulosa layers, suggested that it was indeed the dominant follicle and would ovulate several days later. 


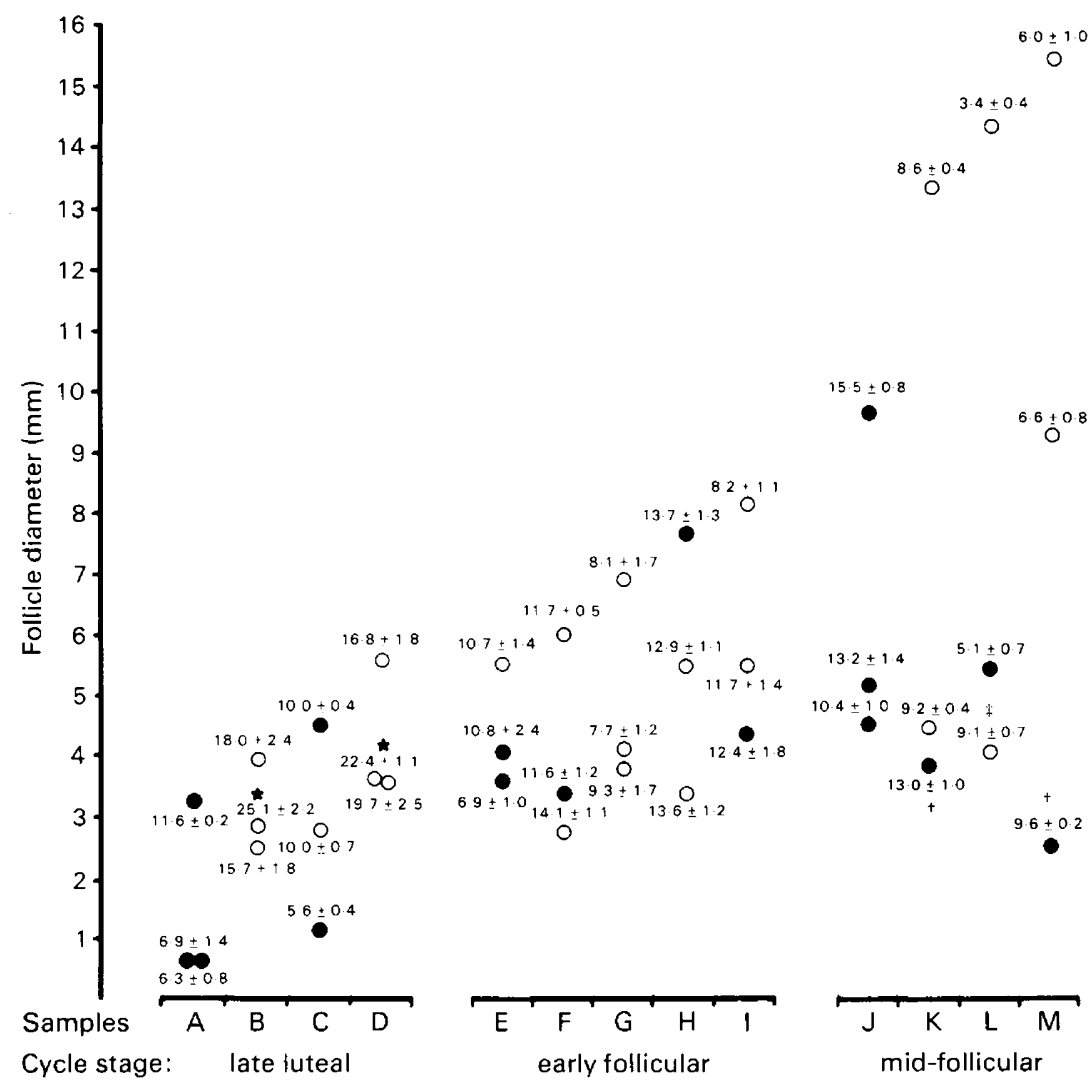

Text-fig. 1. Diameters of the 3 largest healthy follicles in the contralateral ovary (open circles) or in the ovary containing (closed circles) the cyclic corpus luteum (late-luteal phase) or the corpus luteum of the previous cycle (early- and mid-follicular phase). The mitotic index (mean \pm s.e.m., for 4-6 assessments, $\%$ ) of each follicle is shown above each symbol. A, a woman with a cyclic corpus luteum in both ovaries; $J$, the remaining ovary of a chronically hemiovariectomized woman. Mitotic index significantly higher than that of the largest follicle: ${ }^{*} P<0.05 ; \nmid P<0.01 ; \ddagger P<0.001$.

\section{Discussion}

The present results confirm and complement those of McNatty (1982) on the evolution of the largest healthy follicle during the human menstrual cycle. However, in addition they show that the follicle destined to ovulate is chosen from the start of the follicular phase. The diameter of this follicle varies between 5.5 and $8.2 \mathrm{~mm}$, and since it takes about 10 days for a follicle of such size to ovulate (Gougeon, 1982), there is a little doubt that this follicle is indeed that destined to ovulate. The selection of the dominant follicle therefore seems to take place earlier in women than in cynomolgus monkeys (di Zerega \& Hodgen, 1980a).

The observed evolution of the size of the dominant follicle during the follicular phase is in agreement with the morphological and endocrine results from other workers. In the early follicular phase, detectable levels of FSH and high oestradiol-17 concentrations were found only in one follicle, the diameter of which varied between 4 and $6.5 \mathrm{~mm}$ (McNatty, 1982). It was during the mid-follicular phase that the concentration of oestradiol-17ß was much higher in venous plasma draining the ovary containing at least one large follicle $(>1 \mathrm{~cm})$ than in that draining the ovary containing only small follicles (Baird \& Fraser, 1975), and the concentration of this steroid in 
peripheral blood began to rise (Diczfalusy, 1977). As aromatase activity in the human follicle develops from the $9 \mathrm{~mm}$ diameter stage (Hillier, Van den Bogaard, Reichert \& van Hall, 1980), this pattern of secretion agrees with the morphology described between Days 6 and 10. At this point in the cycle the dominant follicle is $13.3 \pm 1.2 \mathrm{~mm}$ in diameter, such values being similar to those seen by Hackelöer, Fleming, Robinson, Adam \& Coutts (1979) who identified a follicle of $11.5 \pm$ $1 \cdot 1 \mathrm{~mm}$ diameter by ultrasound 5 days before the $\mathrm{LH}$ peak.

In the late follicular phase the largest healthy follicle showed all the histological characteristics of a preovulatory follicle as described by Bomsel-Helmreich et al. (1979). During the same period the mean diameter of the largest healthy non-ovulatory follicle decreased significantly. Whether such a decrease is due to a direct (di Zerega \& Hodgen, 1980b) or an indirect (Zeleznik, 1981) effect of the dominant follicle remains to be elucidated.

The use of the mitotic index of the granulosa cells allowed better determination of changes affecting the population of follicles from which the dominant follicle would be recruited. The chosen follicle, seen in the early follicular phase, was certainly recruited from the healthy follicles of 2-5 mm diameter present in the late-luteal phase. At that time the high level of mitotic activity in some follicles, leading to a very rapid development, suggests that, amongst the follicles of similar size present at the end of the cycle, some were more suitable for further development than others.

The interval separating the stage of development attained by follicles in the late-luteal phase (2$5 \mathrm{~mm}$ ) and ovulation is about 2 weeks (Gougeon, 1982). Unlike that in cows (Rajakoski, 1960) and ewes (Brand \& de Jong, 1973) the human ovary does not contain a follicle able to replace the dominant follicle in a few days should it disappear because the largest healthy follicles at such a moment are only 3-6 $\mathrm{mm}$ in diameter. This observation explains the results from the rhesus monkey (Goodman et al., 1977) and man (Nilsson et al., 1982), species in which the destruction of the preovulatory follicle or the young corpus luteum of the cycle is followed by a new ovulation approximately 2 weeks later. Nilsson et al. (1982) found in $5 / 6$ women in which the dominant follicle was excised and in $6 / 10$ women in which the corpus luteum was removed a new ovulation occurred in the ipsilateral ovary. As shown in Table 1, it is considered that in the late-follicular phase the largest healthy follicle, excluding the dominant follicle, is situated in the ovulatory ovary. The same situation exists in the early-luteal phase, although the difference in size between the largest healthy follicles in the two ovaries seems negligible.

A further notable aspect of the present study is the demonstration of an increased number of large healthy follicles in the early-follicular phase. During this stage of the cycle the follicle destined to ovulate is distinguished by its significantly greater size although the diameters of the unselected follicles $(3-5 \mathrm{~mm})$ indicate their advanced stage of development. The usual protocols for ovulation induction using injected gonadotrophins at the start of the cycle often lead to multiple ovulations. At timed laparoscopy after repeated injections of hMG from the 3 rd and 5 th days of the cycle $74 \%$ of women show 4-6 follicles of $>17 \mathrm{~mm}$ diameter (J. Testart, personal communication). Such therapy also leads to multiple pregnancies (Gemzell, Roos \& Loeffler, 1966). It is therefore likely that a gonadotrophin injection at the beginning of the cycle would allow healthy unselected follicles, which would become atretic in a normal cycle, to achieve a stage of maturity that enables them to respond to a preovulatory LH discharge and then ovulate. Under these conditions one might consider that the number of follicles with the opportunity of ovulating after gonadotrophin treatment administered at the start of the cycle is proportional to the number of healthy $3-5 \mathrm{~mm}$ follicles actually present. Therefore, there is probably no rescue of atretic follicles by gonadotrophins in the human ovary, contrary to findings in other species (sheep: Hay \& Moor, 1978; mouse: Braw \& Tsafriri, 1980).

Because of the experimental opportunities it offers, the monkey is usually considered the ideal model for studying human folliculogenesis. However, several aspects of human follicular development (e.g. more precocious selection of the dominant follicle and greater size of the largest healthy follicles) as well as several endocrinological differences in the ovarian cycle (e.g. absence of an oestrogen peak in the luteal phase of the rhesus monkey (Goodman et al., 1977) or cynomolgus 
monkey (Goodman \& Hodgen, 1979)), would suggest that follicular development and its regulatory mechanisms may be different in monkeys and man.

This study was supported by grants from the University Paris-Sud, UER médicale Kremlin Bicêtre (Grant no. 797) and the Institut National de la Santé et de la Recherche Médicale.

We thank Mlle M. C. Levasseur and Dr J. de Mouzon for their advice, Dr D. Mortimer for the English translation and Dr E. Martin, Dr H. Mazabraud, Dr E. Papiernik and Dr M. Prade for providing clinical material.

\section{References}

Baird, D.T. \& Fraser, I.S. (1975) Concentration of oestrone and oestradiol in follicular fluid and ovarian venous blood of women. Clin. Endocr. 4, 259-266.

Bomsel-Helmreich, O., Gougeon, A., Thébault, A., Saltarelli, D., Milgrom, E., Frydman, R. \& Papiernik, E. (1979) Healthy and atretic human follicles in the preovulatory phase: differences in evolution of follicular morphology and steroid content of follicular fluid. J. clin. Endocr. Metab. 48, 686 694.

Brand, A. \& de Jong, W.H.R. (1973) Qualitative and quantitative micromorphological investigations of the tertiary follicle population during the oestrous cycle in sheep. J. Reprod. Fert. 33, 431-439.

Braw, R.H. \& Tsafriri, A. (1980) Effect of PMSG on follicular atresia in the immature rat ovary. $J$. Reprod. Fert. 59, 267-272.

Diczfalusy, E. (1977) Interrelations between plasma levels of biologically active $\mathrm{LH}$ and ovarian and adrenal steroids in the normal menstrual cycle. $J$. Reprod. Fert. 51, 193-201.

di Zerega, G.S. \& Hodgen, G.D. (1980a) Fluorescence localization of luteinizing hormone/human chorionic gonadotrophin uptake in the primate ovary. II. Changing distribution during selection of the dominant follicle. J. clin. Endocr. Metab. 51, 903-907.

di Zerega, G.S. \& Hodgen, G.D. (1980b) The primate ovarian cycle: suppression of human menopausal gonadotrophin-induced follicular growth in the presence of the dominant follicle. J. clin. Endocr. Metab. 50, 819-825.

Gemzell, C.A., Roos, P. \& Loeffler, F.E. (1966) The clinical use of pituitary gonadotrophins in women. $J$. Reprod. Fert. 12, 49-64.

Goodman, A.L. \& Hodgen, G.D. (1979) Between-ovary interaction in the regulation of follicle growth, corpus luteum function, and gonadotropin secretion in the primate ovarian cycle. II. Effects of luteectomy and hemiovariectomy during the luteal phase in cynomolgus monkeys. Endocrinology 104, 1310-1316.

Goodman, A.L., Nixon, W.E., Johnson, D.L. \& Hodgen, G.D. (1977) Regulation of folliculogenesis in the rhesus monkey: selection of the dominant follicle. Endocrinology 100, 155-161.

Gougeon, A. (1979) Qualitative changes in medium and large antral follicles in the human ovary during the menstrual cycle. Annls Biol. anim. Biochim. Biophys. 19, 1461-1468.

Gougeon, A. (1982) Rate of follicular growth in the human ovary. In Follicular Maturation and Ovulation, pp. 155-163. Eds R. Rolland, E. V. van Hall, S. G. Hillier, K. P. McNatty \& J. Schoemaker. Excerpta Medica, Amsterdam.

Hackelöer, B.J., Fleming, R., Robinson, H.P., Adam, A.H. \& Coutts, J.R.T. (1979) Correlation of ultrasonic and endocrinologic assessment of human follicular development. Am. J. Obstet. Gynec. 135, $122-128$.

Hay, M.F. \& Moor, R.M. (1978) Changes in the Graafian follicle population during the follicular phase of the oestrous cycle. In Control of Ovulation, Ch. 11, pp. 177-196. Eds. D. B. Crighton, G. R. Foxcroft, N. B. Haynes, \& G. E. Lamming. Butterworth, London.

Hillier, S.G., Van den Bogaard, A.M.S., Reichert, L. \& van Hall, E.V. (1980) Intraovarian sex steroid hormone interactions and the regulation of follicular maturation: aromatization of androgens by human granulosa cells in vitro. J. clin. Endocr. Metab. 50, 640647.

Hodgen, G.D. (1982) The dominant ovarian follicle. Fert. Steril. 38, 640-647.

MeNatty, K.P. (1982) Ovarian follicular development from the onset of luteal regression in humans and sheep. In Follicular Maturation and Ovulation, pp. 1-18. Eds R. Rolland, E. V. van Hall, S. G. Hillier, K. P. McNatty \& J. Schoemaker. Excerpta Medica, Amsterdam.

Nilsson, L., Wikland, M. \& Hamberger, L. (1982) Recruitment of an ovulatory follicle in the human following follicle-ectomy and luteectomy. Fert. Steril. 37, 30-34.

Rajakoski, E. (1960) The ovarian follicular system in sexually mature heifers with special reference to seasonal, cyclical and left-right variations. Acta endocr., Copenh., Suppl. 52, 7-68.

Zeleznik, A.J. (1981) Premature elevation of systemic estradiol reduces serum levels of follicle-stimulating hormone and lengthens the follicular phase of the menstrual cycle in rhesus monkeys. Endocrinology 109, 352-355. 